\title{
SÍNDROME DA BANDA AMNIÓTICA: RELATO DE CASO
}

\author{
AMNIOTIC BAND SYNDROME: CASE REPORT
}

Francisco Carlos Salles Nogueira', Robert Bicalho da Cruz ${ }^{2}$, Leonardo Pelucci Machado ${ }^{3}$, Bernardo Luiz Fornaciari Ramos ${ }^{4}$, João Lopo Madureira Júnior ${ }^{5}$, Roberto Zambelli de Almeida Pinto ${ }^{6}$

\section{RESUMO}

A síndrome da banda amniótica é uma desordem congênita rara que pode resultar em defeitos corporais diversos (bandas de constrição, amputação, deformidades craniofaciais, anomalias viscerais etc). Sua incidência é estimada em cerca de 1:1.200 a 1:15.000 nascidos vivos. O acometimento das extremidades é o mais frequente. Relatamos um caso envolvendo o membro superior esquerdo e ambos os membros inferiores de um recémnascido operado no Hospital Mater Dei em Belo Horizonte.

Descritores - Síndrome de Bandas Amnióticas; Anormalidades Congênitas; Recém-Nascido

\section{ABSTRACT}

The amniotic band syndrome is a rare congenital disorder that can result in various body effects (constriction bands, amputation, craniofacial and visceral anomalies, etc). Its incidence is estimated at approximately 1:1.200 to 1:15.000 live births. The involvement of the extremities is the most frequent. We report a case involving the left upper limb and both inferior limbs of a male, new born, operated at Mater Dei Hospital in Belo Horizonte.

Keywords - Amniotic Band Syndrome; Congenital Abnormalities; Infant, Newborn

dos membros inferiores que consistem em constrições anulares assimétricas, atrofia distal, amputações intrauterinas congênitas, sindactilia e acrossindactilia (sindactilia fenestrada) $)^{(4)}$, linfedema, luxação congênita do quadril, pseudoartrose da tíbia, pé torto congênito, pé metatarso varo, pé talo vertical ${ }^{(2,5-7)}$, elevado índice de óbito e incompatibilidade com a vida ${ }^{(8)}$. Tem incidência de $1: 1.200$ a $1: 15.000$ nascidos $\operatorname{vivos}^{(9)}$.

Sua etiologia é desconhecida, sendo propostos dois mecanismos patogênicos principais: a teoria extrínseca, proposta por Torpin e Faulkner ${ }^{(10)}$, em 1966, e demonstrada laboratorialmente por Kino ${ }^{(11)}$, em 1975, segundo a qual ocorre a ruptura precoce do âmnio que proporcionaria o contato do feto com a superfície coriônica

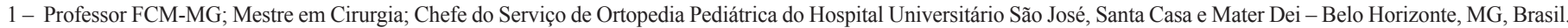

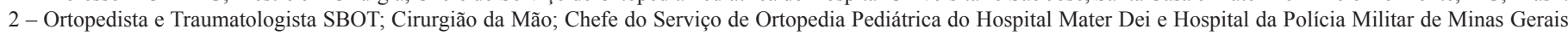
Belo Horizonte, MG, Brasil.

3 - Ortopedista Pediátrico do Hospital Santa Casa de Belo Horizonte - Belo Horizonte, MG, Brasil.

4 - Ortopedista Pediátrico do Departamento de Ortopedia Pediátrica do Hospital Mater Dei - Belo Horizonte, MG, Brasil.

5 - Médico Graduado pela UFMG; Residente do Terceiro Ano em Ortopedia e Traumatologia do Hospital Mater Dei - Belo Horizonte, MG, Brasil.

6 - Ortopedista e Traumatologista SBOT; Cirurgião do Pé e Tornozelo do Hospital Mater Dei - Belo Horizonte, MG, Brasil.

Trabalho realizado no Departamento de Ortopedia Pediátrica do Hospital Mater - Belo Horizonte, MG, Brasil.

Correspondência: Bernardo Luiz Fornaciari Ramos, Rua Deputado Álvaro Sales, 95, Santo Antonio - 30350-250 - Belo Horizonte, MG, Brasil.

E-mail: bernardolframos@hotmail.com

Trabalho recebido para publicação: 24/08/2011, aceito para publicação: 31/08/2011.

Os autores declaram inexistência de conflito de interesses na realização deste trabalho / The authors declare that there was no conflict of interest in conducting this work 
amniótica, advindo, então, a aderência dessa estrutura a vários segmentos fetais, que levaria as bandas fibrosas a aprisionar o corpo fetal. Favorável a esta teoria existem relatos de casos relacionados à realização da amniocentese no primeiro trimestre de gestação ${ }^{(12)}$. $\mathrm{O}$ segundo mecanismo baseia-se na teoria endógena, proposta por Streeter $^{(13)}$, em 1930, que estabelece a ocorrência de um defeito no plasma germinativo com a ruptura vascular e alteração da morfogênese durante a fase da gastrulação ${ }^{(1)}$. Esta teoria encontra bases atuais com estudos de malformações diversas relacionadas à displasia de Streeter ${ }^{(14,15)}$.

O diagnóstico da displasia de Streeter pode ser feito desde o período intraútero por meio do exame ultrassonográfico e melhor avaliada com o advento do estudo tridimensional ${ }^{(16)}$. Trata-se de um exame de grande importância, uma vez que, como mencionado anteriormente, as anomalias musculoesqueléticas podem manifestarse como parte de uma síndrome ou ser acompanhadas de outras numerosas condições como alterações genéticas. Seu diagnóstico precoce é importante em decidir os cuidados perinatais e em ajudar a orientar os pais acerca dos possíveis efeitos das anomalias associadas ${ }^{(3,17,18)}$. A fração beta do hormônio gonadotrofina coriônica (ß-HCG) pode encontrar-se elevada como resposta placentária em tentar compensar a restrição do crescimento fetal secundário ao estrangulamento causado pela brida amniótica, como caso relatado de óbito fetal intrauterino por constrição do cordão umbilical ${ }^{(6)}$.

O tratamento consiste na liberação das bandas amnióticas circunferenciais. Pode-se associar zetaplastias múltiplas ${ }^{(19)}$ e únicas. Estas últimas apresentando menor índice de complicações e recuperação mais rápida dos pacientes ${ }^{(20,21)}$. A cirurgia deve ser realizada o mais precocemente possível, em virtude das afecções cutâneas, edemas linfáticos e até gangrena do segmento distal ${ }^{(21)}$, havendo relatos de liberações bem sucedidas feitas intraútero por via endoscópica ${ }^{(9)}$.

\section{RELATO DO CASO}

Em janeiro de 2004 avaliou-se no berçário da maternidade do Hospital Mater Dei um recém-nascido $(\mathrm{RN})$ de um dia de vida, do sexo masculino, nascido de parto cesáreo a termo. O mesmo apresentava déficit circulatório progressivo no membro inferior esquerdo (MIE) com proposta cirúrgica de amputação (Figura 1).

Diagnosticou-se displasia de Streeter. O RN apresentava bandas de constrição em ambos os membros inferiores. No lado esquerdo a lesão era mais grave sendo que a mão ipsilateral também apresentava acrossin- dactilia e amputação intraútero distal dos quirodáctilos esquerdos (Figura 2).

O RN necessitou de descompressão cirúrgica de emergência. $\mathrm{O}$ objetivo era a preservação dos membros. O procedimento foi realizado no mesmo dia da avaliação com relativo sucesso (Figura 3 ).

Depois do procedimento, realizaram-se estudos radiográficos a fim de melhor avaliar o RN. Observou-se pseudoartrose dos ossos da perna esquerda e pé torto congênito ipsilateral (Figura 4). Após controles quinzenais, em maio de 2004 realizou-se nova intervenção cirúrgica, uma vez que se observou linfedema e diminuição do retorno venoso no MIE. Nesse momento, foram realizadas liberações de partes moles (zetaplastias) em ambos os membros e fixação com fios intramedulares da pseudoartrose da tíbia esquerda que apresentava franca mobilidade no foco (Figura 5). Em março de 2005, fez-se a correção do pé torto congênito utilizando a incisão de Cincinnati e a técnica de McKay. Obteve-se sucesso conseguindo-se pés plantígrados. Em maio de 2005, as deformidades da mão foram abordadas com liberação da acrossindactilia e, em agosto de 2005, realizou-se nova liberação cicatricial com abordagem das retrações residuais.

O pós-operatório transcorreu sem intercorrências, com o salvamento dos três membros acometidos, consolidação da pseudoartrose dos ossos da perna esquerda, correção das deformidades do pé torto congênito e da acrossindactilia (Figuras 6, 7 e 8).

A criança manteve acompanhamento em regime ambulatorial e encontra-se plenamente integrada às atividades da infância, com bom resultado estético e funcional, consolidação da pseudoartrose, apoio com pés plantígrados e melhora da preensão da mão (Figura 9). Atualmente, aos sete anos de idade, apresenta discrepância dos membros inferiores devido ao encurtamento de $1,8 \mathrm{~cm}$ da perna esquerda (Figura 10) aferida por meio de escanometria digital em seu último retorno.

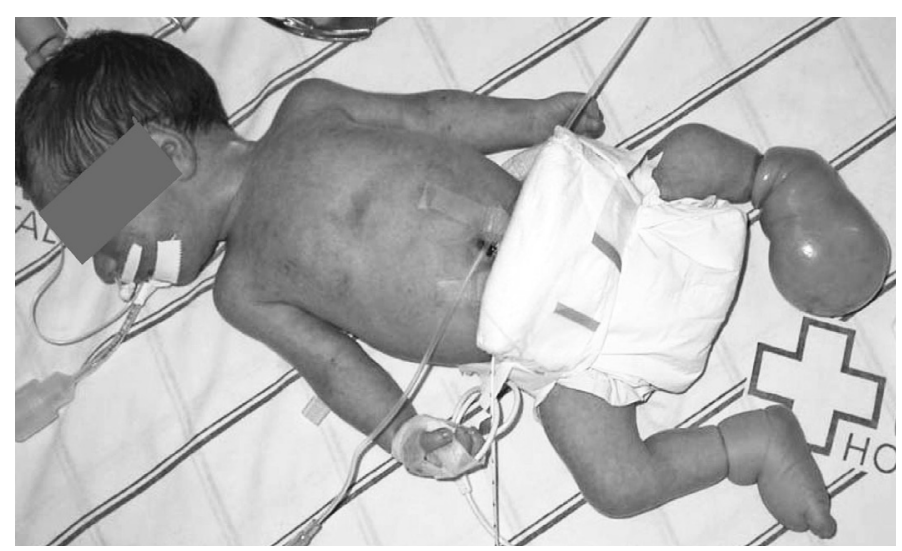

Figura 1 - Estado geral do RN examinado (idade: um dia). 


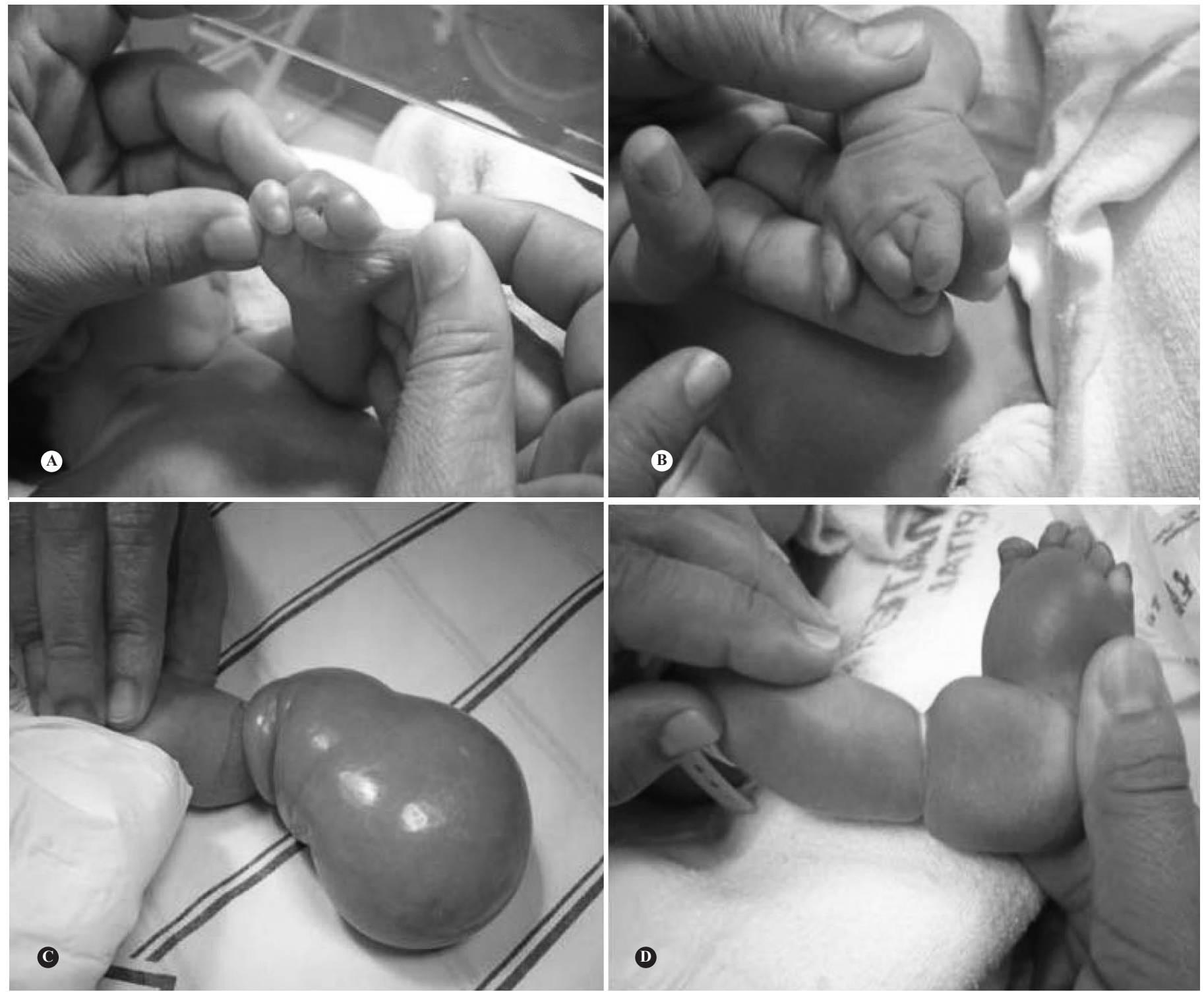

Figura 2 - Detalhes dos membros. A e B) Acrossindactilia. C) Banda de constrição em membro inferior esquerdo. D) Banda de constrição em membro inferior direito.

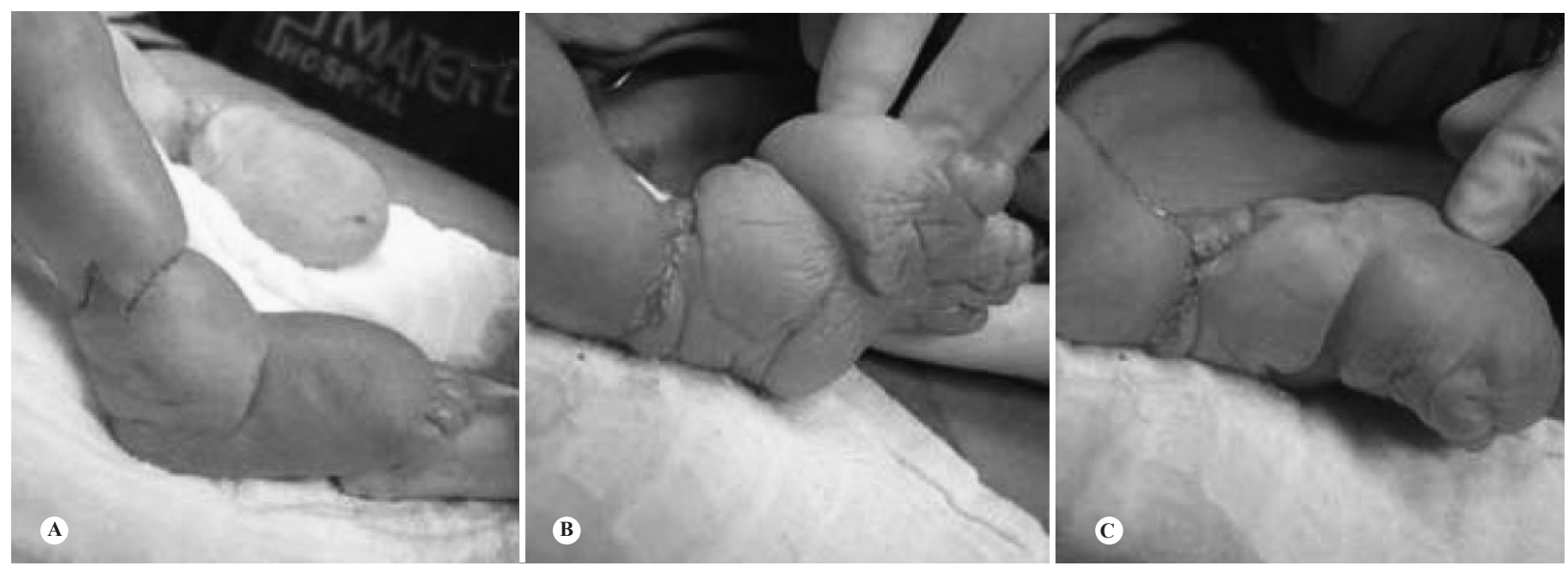

Figura 3 - Peroperatório após liberação das bandas de constrição. A) Liberação em membro inferior direito (zetaplastia). B e C) Liberação em membro inferior esquerdo (zetaplastia). 

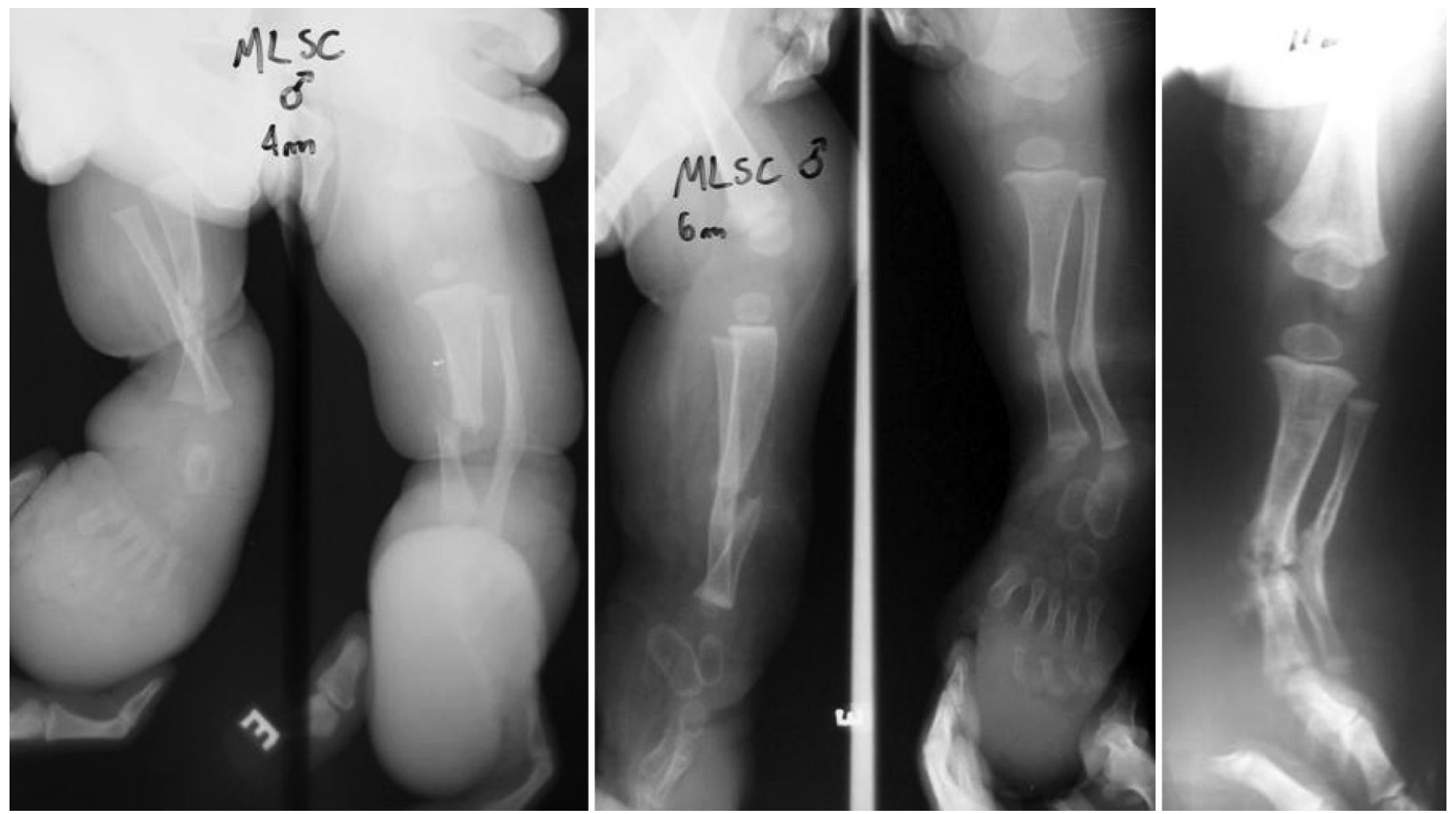

Figura 4 - Estudos radiográficos do membro inferior esquerdo com diagnóstico de pseudoartrose dos ossos da perna e pé torto congênito.
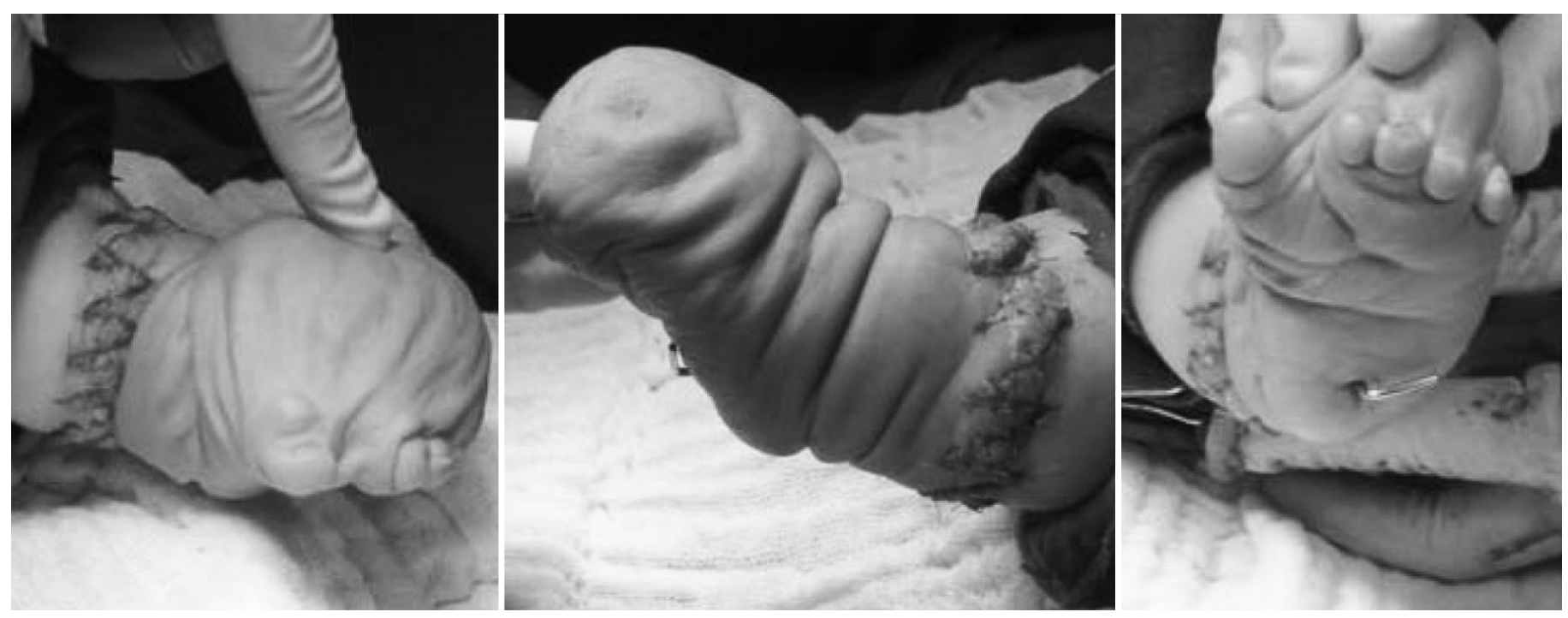

Figura 5 - Correção da pseudoartrose dos ossos da perna esquerda e deformidade do pé torto congênito.

\section{DISCUSSÃO}

A displasia de Streeter é uma afecção que pode levar a quadros clínicos graves com necessidade de intervenções cirúrgicas de urgência em alguns casos. Essa criança apresentou manifestações graves compatíveis com as descritas na literatura e necessitou de abordagem emergencial devido ao déficit perfusional encontrado.

As constrições anulares em ambos os membros in- feriores (MMII), a pseudoartrose da tíbia, o pé torto congênito, a acrossindactilia e a amputação intrauterina da porção distal dos dedos da mão ipsilateral são achados comuns quando diagnosticada a síndrome das bandas amnióticas.

Muitas vezes, a única opção cirúrgica é a amputação da extremidade acometida. Nesse caso, era a sugestão de procedimento descrita no pedido de interconsulta devido à gravidade das constrições e da repercussão sistêmica 

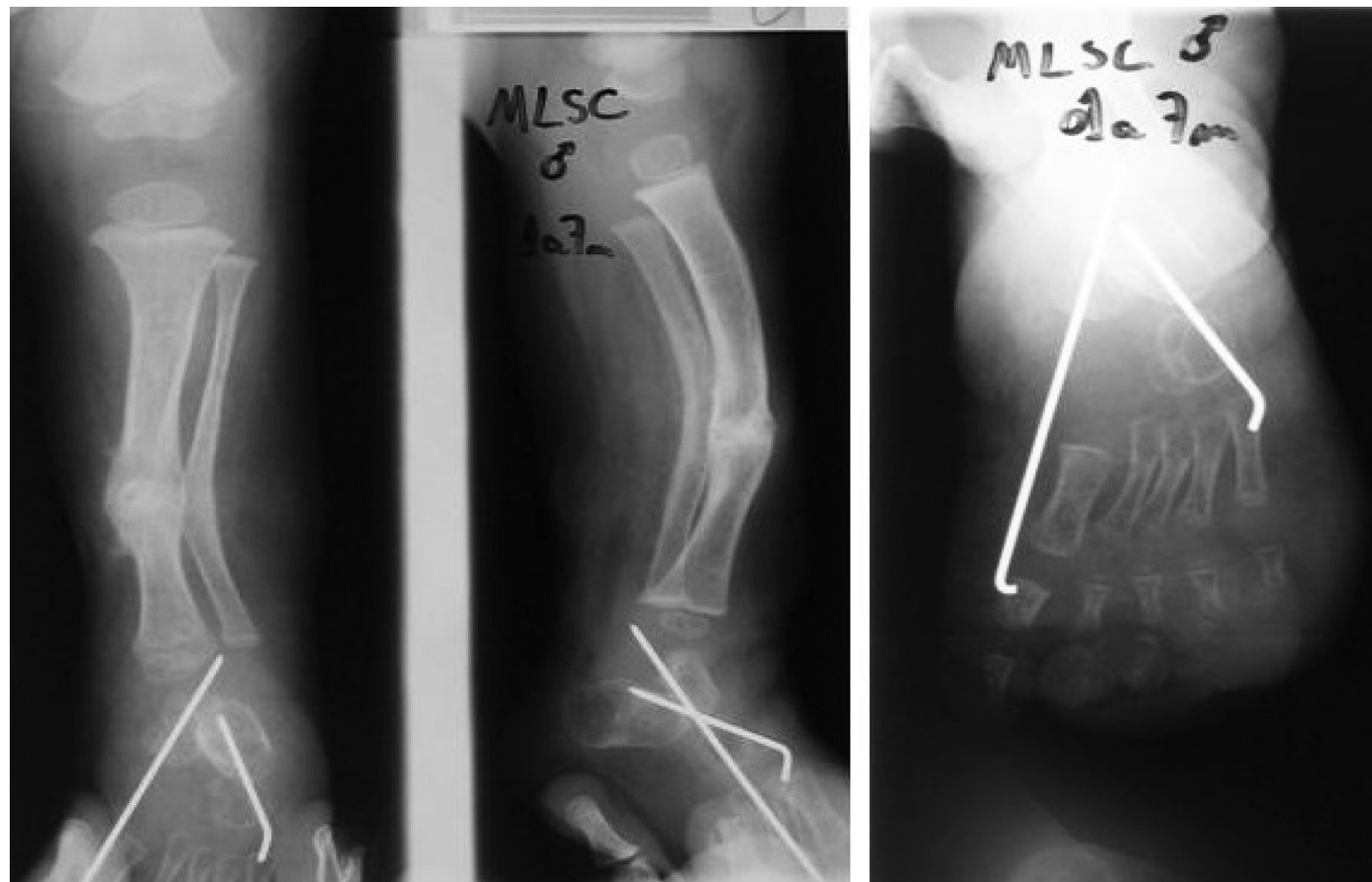

Figura 6 - Estudos radiográficos mostrando a correção da pseudoartrose dos ossos da perna esquerda e deformidade do pé torto congênito (idade: um ano e sete meses).

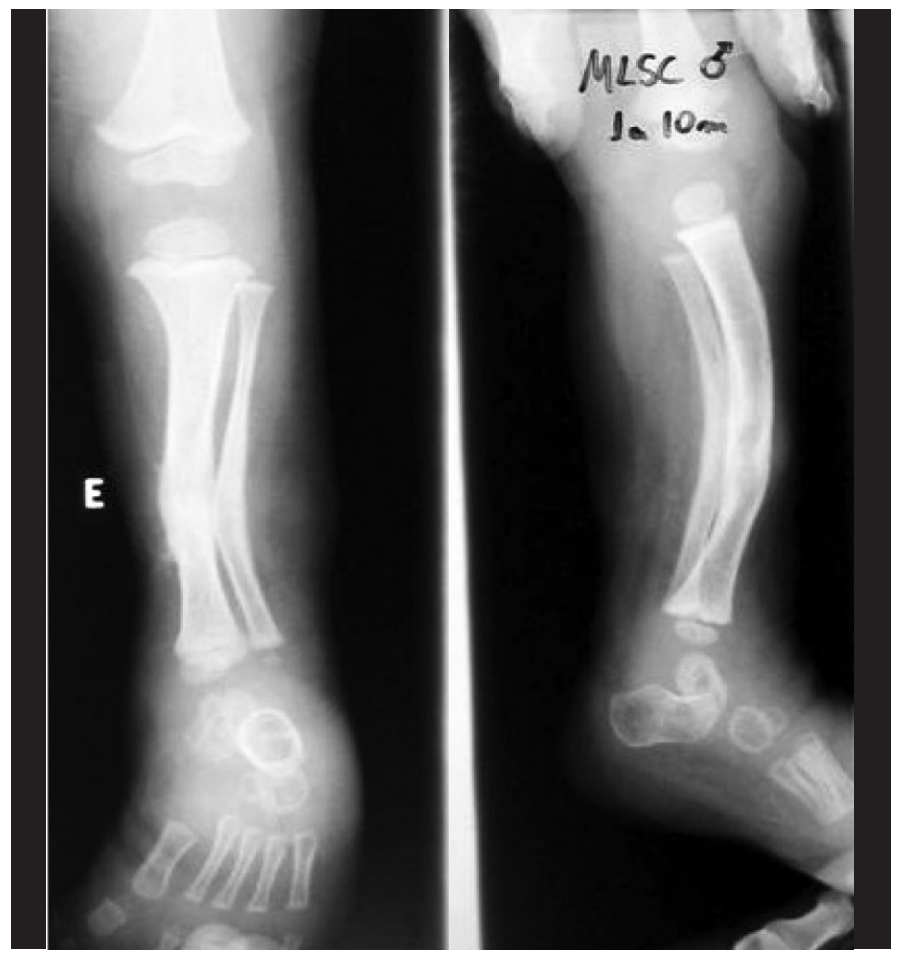

Figura 7 - Estudos radiográficos de acompanhamento mostrando consolidação da pseudoartrose dos ossos da perna e retirada dos fios de Kirschner utilizados na correção da deformidade do pé torto congênito (idade: um ano e 10 meses). consequente. De maneira concordante com a literatura, o diferencial na condução do caso foi o pronto diagnóstico e a liberação cirúrgica das bandas de contrição do MIE em caráter emergencial, com correção das deformidades associadas em segundo tempo, após melhor avaliação destas e garantia da perfusão adequada dos membros acometidos.

$\mathrm{O}$ tratamento preconizado na literatura vigente consiste na liberação das bandas amnióticas circunferenciais. Zetaplastias múltiplas ${ }^{(19)}$ ou únicas são ótimas opções. Menor índice de complicação é descrito nos procedimentos únicos ${ }^{(20,21)}$. No presente caso clínico, as zetaplastias foram realizadas de forma seriada. No primeiro procedimento, o objetivo principal era preservar o MIE, evitando uma amputação precoce.

A pseudoartrose da tíbia e o pé torto congênito também têm indicação cirúrgica descrita. No entanto, não apresentam caráter emergencial e devem ser abordados em um momento adequado após evolução favorável dos procedimentos principais.

Durante o acompanhamento do paciente observou-se discrepância leve dos membros inferiores sem repercussão funcional importante. Os achados clínicos eram 

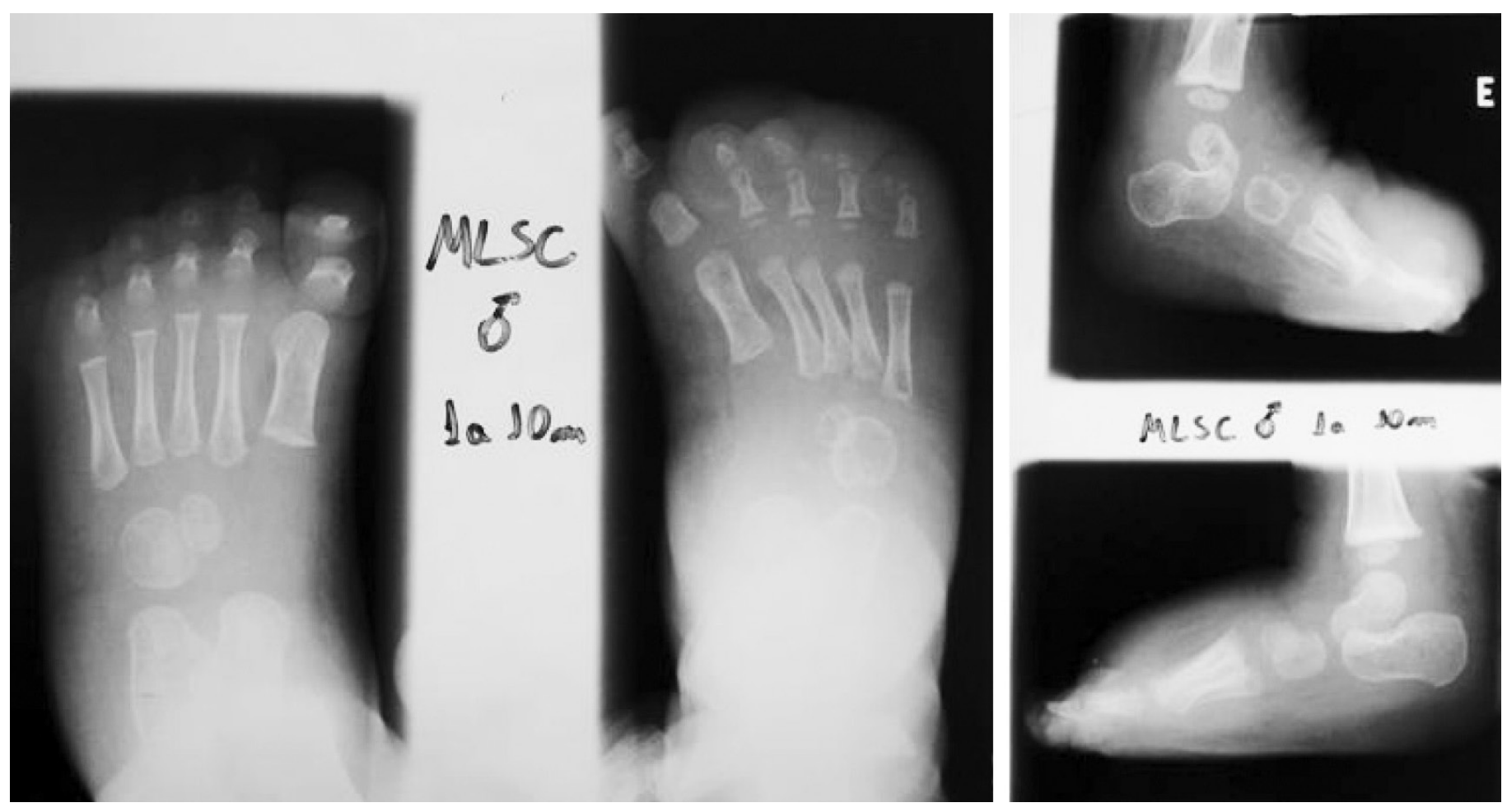

Figura 8 - Detalhe dos estudos radiográficos do resultado da correção cirúrgica da deformidade do pé torto congênito (idade: um ano e 10 meses).

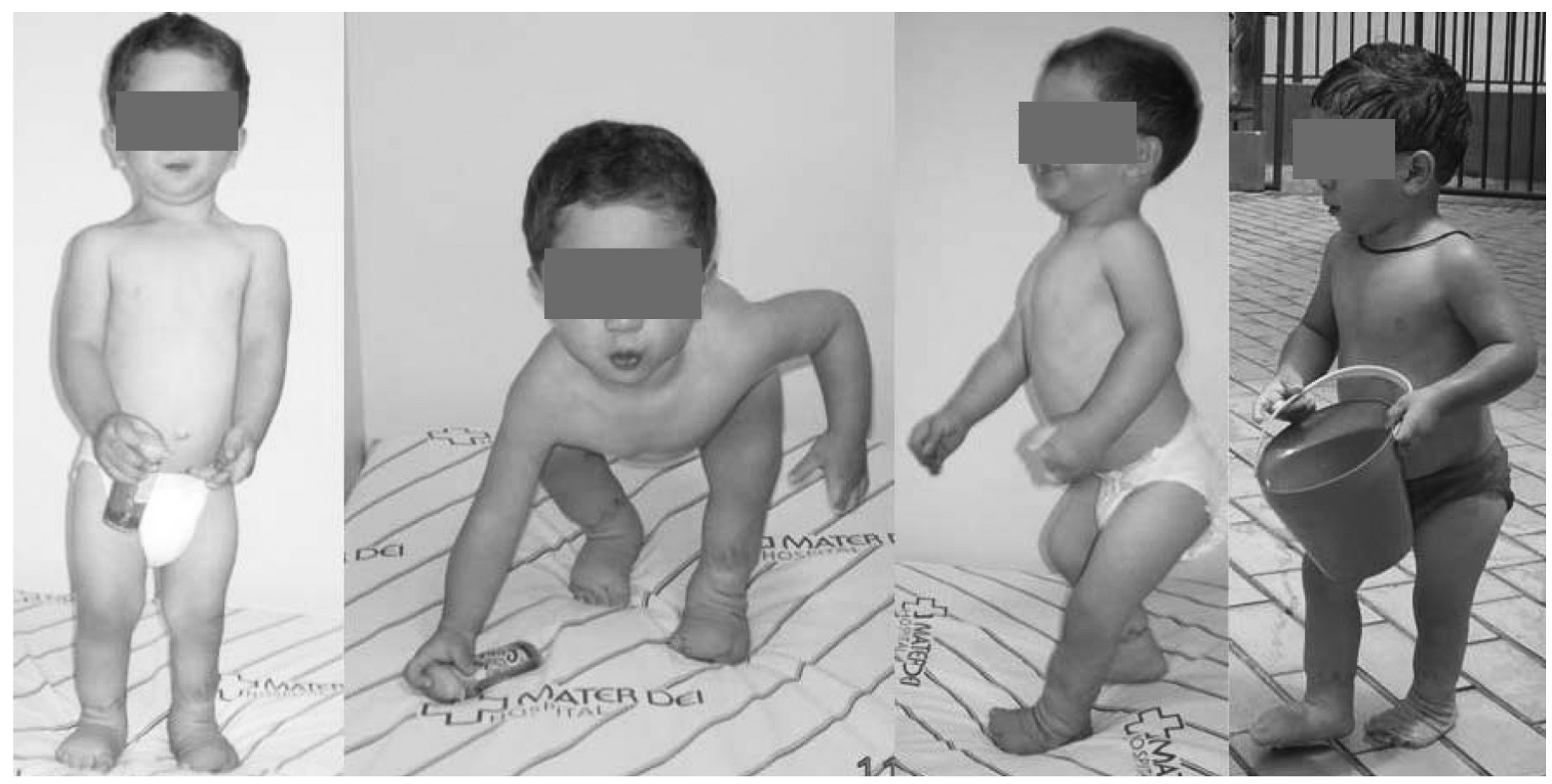

Figura 9 - Criança realizando atividades da vida diária. Observar a funcionalidade dos membros. Ao exame apresentava marcha adequada e pé esquerdo plantígrado. Mão esquerda igualmente funcional (idade: três anos).

uma discreta claudicação e uma escoliose postural leve. Prescreveu-se palmilha compensatória. Avaliações clínicas e radiológicas têm sido realizadas frequentemente. Em caso de aumento da discrepância dos MMII pode ser necessária abordagem cirúrgica para correção da mesma.
A criança está muito bem adaptada às deformidades residuais. Pratica tae kwon do, sendo campeã regional em sua categoria (conquistou duas medalhas de ouro em competições esportivas). Os familiares também estão muito satisfeitos com os resultados estéticos. 


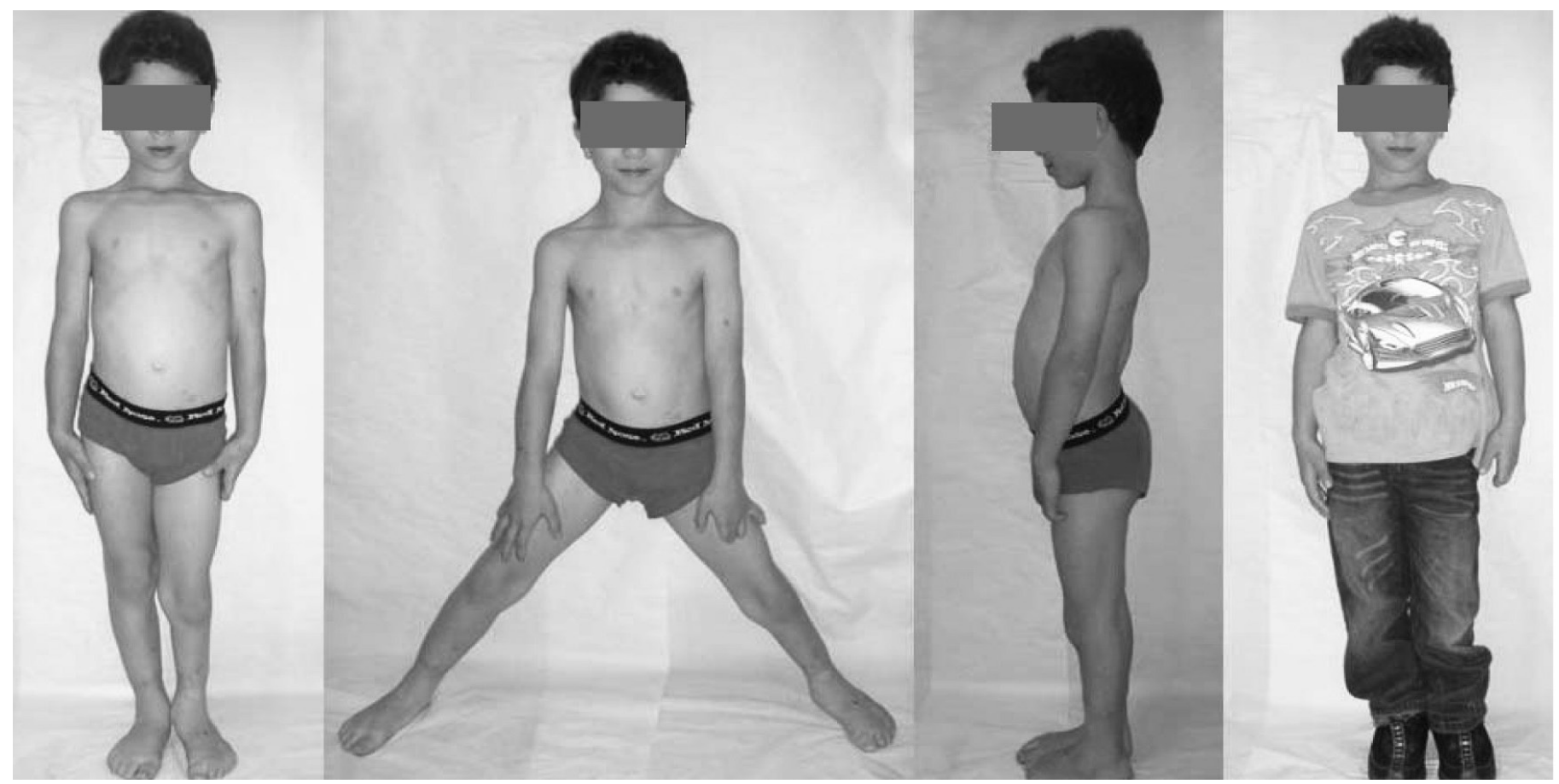

Figura 10 - Criança atualmente. Ótima evolução. Discrepância leve dos membros inferiores confirmada por escanometria (idade: sete anos).

\section{CONCLUSÃO}

O tratamento da displasia de Streeter deve ser feito, muitas vezes, em caráter de emergência. Salvar os membros acometidos pelas constrições anulares e garantir a funcionalidade dos mesmos deve ser preocupação básica. Posterior aprofundamento propedêutico para programação da correção das deformidades associadas é mandatório, uma vez já afastado o risco de isquemia ou até mesmo óbito do recém-nascido. $\mathrm{O}$ acompanhamento do paciente deve ser feito até atingir-se a plena maturidade esquelética permitindo o diagnóstico de possíveis deformidades secundárias e a correção das mesmas no momento mais adequado.

\section{REFERÊNCIAS}

1. Gaete M, Araníbar L, Villalba V, Tellerías L. Síndrome de bridas amnióticas: a propósito de um caso. Rev Chil Dermatol. 2008;24(1):55-6.

2. Costa EM, Alves MP, Fraga CE, Silva Júnior JA, Daher O. Síndrome das bandas de constrição congênita. Estudo de 16 casos. Rev Bras Ortop. 1996;31(4):341-6.

3. Lobato G. Brida amniótica: achados sonográficos e correlações etiopatogênicas. Femina. 2008;36(3):159-63.

4. Pardini Junior AG, Santos MA, Freitas AD. Bandas de constrição congênitas. Acta Ortop Bras. 2001;9(2):5-12.

5. Walter JH, Goss LR, Lazzara AT. Amniotic band syndrome. J Foot Ankle Surg. 1998;37(4):325-33.

6. Sifakis S, Mantas N, Konstantinidou A, Koukoura O, Avgoustinakis E, Koumantakis E. A stillborn fetus with amniotic band syndrome and elevated levels of alpha-fetoprotein plus beta-human chorionic gonadotropin: a case report. Fetal Diagn Ther. 2008;24(2):111-4.

7. Pedersen TK, Thomsen SG. Spontaneous resolution of amniotic bands. Ultrasound Obstet Gynecol. 2001;18(6):673-4.

8. Orellana HR, Paublo MM, Bustos VJ, Ramirez HP, Gutiérrez CJ, Andreani FS, et al. Síndrome de brida amniótica y complejo "limb-body-wall": a propósito de um caso clínico. Bol Hosp San Juan de Dios. 2004;51(6):340-3.

9. Ronderos-Dumit D, Briceño F, Navarro H, Sanchez N. Endoscopic release of limb constriction rings in utero. Fetal Diagn Ther. 2006;21(3):255-8.

10. Torpin R, Faulkner A. Intrauterine amputation with the missing member found in the fetal membranes. JAMA. 1966;198(2):185-7

11. Kino Y. Clinical and experimental studies of the congenital constriction band syndrome, with an emphasis on its etiology. J Bone Joint Surg Am. 1975;57(5):636-43.

12. Rebello CM, Leone CR, Zugaib M, Ramos JL, Gonzáles $\mathrm{CH}$. Sindrome da brida amniótica. Pediatria (Säo Paulo). 1990;11/12:26-9

13. Streeter GL. Focal deficiencies in fetal tissues and their relation to intra-uterine amputation. Contrib Embryol. 1930;22(1):1-44.

14. Ruggieri M, Spalice A, Polizzi A, Roggini M, lannetti P. Bilateral periventricular nodular heterotopia with amniotic band syndrome. Pediatr Neurol. 2007;36(6):407-10.

15. Chen CP. Syndromes, disorders and maternal risk factors associated with neural tube defects (III). Taiwan J Obstet Gynecol. 2008;47(2):131-40.

16. Jure YR. Estudio tridimensional de bandas amnióticas y diagnósticos diferenciales. Rev Chil Ultrason. 2004;7(1):4-9.

17. Ryu JK, Cho JY, Choi JS. Prenatal sonographic diagnosis of focal musculoskeletal anomalies. Korean J Radiol. 2003;4(4):243-51.

18. Pons G.,Andrés;Saés A., Rodrigo;Sepúlveda L., Waldo. Brida amniótica, sinéquia intrauterina y tabique mulleriano:etiopatogenia, diagnóstico difererncial y prognóstico/amniotic band, intrauterine synechiae and mullerian septum: etiopathogenic, differencial diagnosis and prognosis. Rev. Chil. Ultrason;8(2):51-58,2005.

19. Vásquez Rueda, F; Ayala Montoro, J; Blanco Lopez,F; Gutierrez Canto, M; Valdiviesso Garcia, J.L;Ocanã Losa, L.M. Síndrome de Bandas de constricción congênitas/Congenital constriction band syndrome. Ver.cir. infant;9(3):163-7,sep.1999.

20. Capdevila Leonori, Roman; Nualart Hernández, Luis. Banda amniótica circunferenciales liberación em um tiempo quirúrgico;circumferencial amiotic bands. Release in one operating time. Ver. mex.ortop.traumatol:13(1):60-2,ene.-feb.1999.

21. Monteiro Junior, Araldo Ayres; Modolin, Miguel Luiz Antonio;Domingos,Maurício de Maio;Freitas, Renato da Silva. Bridas amnióticas: tratamento cirúrgico/amniotic bands:surgical treatment. Pediatria(São Paulo);17(1):39-41,jan.-mar.1995. 